\title{
Sistemas eletromagnéticos usando balanceamento de indução magnética para uso em Geofísica Rasa e Arqueologia.
}

Francisco Yukio Hiodo, Hugo F. Saar, Edgar D. Bronizeski, Kleiton Blane, Nilton P. Silva

Instituto de Astronomia, Geofísica e Ciências Atmosféricas da Universidade de São Paulo( IAG-USP )

E-Mail: francisc@iag.usp.br, nilton@iag.usp.br

Copyright 2004, SBGf - Sociedade Brasileira de Geofísica

Este texto foi preparado para a apresentação no I Simpósio Regional da Sociedade Brasileira de Geofísica, São Paulo, 26-28 de setembro de 2004. Seu conteúdo foi revisado pela Comissão Tecno-científica do I SR-SBGf mas não necessariamente representa a opinião da SBGf ou de seus associados. E proibida a reprodução total ou representa a opinião da SBGf ou de seus associados. E proibida a reprodução total
parcial deste material para propósitos comerciais sem prévia autorização da SBGf.

\section{Resumo}

Um equipamento de campo magnético indutivo usando o conceito de número de indução baixo foi desenvolvido, para localização de alvos condutores rasos, em sub-superfície. A sua grande portabilidade, resolução e rapidez de aquisição de dados torna-o ideal para vários trabalhos em lixões, aterros sanitários, em Geotecnia e Arqueologia. Um datalogger usando microcontrolador de baixo custo programado em assembler foi construído para aquisição rápida dos dados, e transferência posterior para notebooks.

\section{Introdução}

O sistema foi projetado para medidas, sem contato físico equipamento- solo, das condutividades elétricas aparentes de alvos soterrados, usando 0 método de sondagem eletromagnética dipolar.

A profundidade efetiva de exploração é de aproximadamente 6 metros, tornando-o ideal para muitas pesquisas geotécnicas e de contaminações de aquíferos pelos chorumes de lixões ou de aterro sanitário.

$O$ instrumento permite mapear contaminantes de lençóis freáticos ou quaisquer anomalias subsuperficiais associadas com mudanças de condutividade elétrica do terreno, sem usar eletrodos ou qualquer contacto com o solo. Utilizando- se o método eletromagnético indutivo, perfis de condutividade elétrica aparente podem ser feitos, em situações de resistividade elétrica superficial elevada, tais como coberturas de arenito, asfalto, concreto, etc.

Os valores da condutividade elétrica calculada em $\mathrm{mS} / \mathrm{m}$ e o da componente em fase são apresentados simultâneamente no display de 2 linhas, com 16 caracteres por linha, em tempo real. A componente em fase é particularmente útil na detecção de corpos mineralizados rasos, e na localização de tambores metálicos enterrados em levantamentos de aterros sanitários, de tubos, e de outros perfis metálicos ferrosos ou não ferrosos. O valor relativo da componente real do campo magnético vertical, aumenta a capacidade do instrumento na detecção de objetos metálicos soterrados. Estas características tornam o equipamento ideal para várias aplicações arqueológicas.

\section{Descrição do equipamento desenvolvido}

Basicamente, o sistema é constituído de 2 bobinas, uma transmissora $\mathrm{Tx}$ e outra receptora $\mathrm{Rx}$, presas nas extremidades de uma haste de $4 \mathrm{~m}$, e dispostas de modo que as linhas de força do campo magnético do transmissor $\mathrm{Hp}$ não induzam sinal na bobina receptora, na ausência de condutor (Fig.1). Na presença de um alvo tem- se um campo secundário $\mathrm{Hs}$, que gera uma tensão na saída da bobina receptora $R x$. Este sinal é amplificado e tratado por 2 demoduladores, em fase e em quadratura, sincronos com as referências provenientes de Tx. Os sinais DC filtrados destes amplificadores são processados por um microcontrolador dotado de conversor AD de 10 bits, que efetua operações algébricas e apresenta simultaneamente valores de condutividade elétrica e da componente em fase do campo Hs (Fig.2). Os cálculos são efetuados usando o conceito de número de indução baixo Os 2 valores determinados, juntamente com a identificação do ponto de medida são gravados em memórias não voláteis, para posterior transferência para um notebook.

Perfis podem ser rapidamente levantados, e medidas contínuas com pequenas variações de condutividade podem ser realizadas com o equipamento dotado de um compacto sistema digital de aquisição de dados, conectado a um pequeno indicador de distância percorrida (hodômetro).

\section{Funcionamento}

Os eixos das bobinas transmissora Tx e receptora $\mathrm{Rx}$, presas numa mesma haste de $4 \mathrm{~m}$ (Fig.1) são ajustados de modo que o fluxo do campo magnético direto $\mathrm{Hp}$ na bobina Rx seja nulo, em todo instante. Os eixos das duas bobinas devem estar paralelos e formando ângulo de $54,74^{\circ} \mathrm{com}$ a horizontal (Sinha \& Collett, 1973). Nesta configuração os alvos condutores de interesse normalmente situam-se nas regiões onde os gradientes do campo variável $\mathrm{Hp}$ da bobina $\mathrm{Tx}$ são maiores, quando comparados com sistemas comuns de detecção, onde as bobinas são ortogonais, distanciadas de $2 \mathrm{~m}$, no máximo. Neste arranjo clássico o eixo da bobina transmissora é horizontal e o da receptora, vertical, para que se tenha o cancelamento do campo primário no receptor.

Os dados foram programados para serem adquiridos e apresentados no display a cada $50 \mathrm{~cm}$. Os pulsos de disparo para controle de espaço percorrido provem de um pequeno disco de alumínio de perímetro $25 \mathrm{~cm}$, que gira livremente. Sobre o disco estão enroladas algumas espiras de um fio de algodão industrial cuja extremidade está presa na origem da linha 
de medida. O disparo é realizado por um conjunto miniaturizado imã- interruptor tipo reed, que aciona o contador do PIC.

O microcontrolador usado de tecnologia RISC tem internamente um conversor $A D$, de 10 bits e 8 canais de entrada, responsável pela conversão das tensões de saída dos demoduladores sincronos, referentes aos campos em fase e em quadratura do campo secundário $\mathrm{Hs}$ e da tensão proporcional ao campo $\mathrm{Hp}$. Com estes valores, efetua o cálculo da condutividade elétrica aparente do solo em tempo real, e grava os dados de interesse em memórias $\mathrm{E}^{2} \mathrm{PROM}$. Estas memórias não voláteis têm capacidade de registro para 10000 pontos de medida. Estes dados gravados podem ser transferidos para um notebook, via comunicação serial RS232C. O programa residente para controle do microcontrolador é gravado em suas memórias FLASH, através de um compilador assembler fornecido pelo fabricante.

Paralelamente foi desenvolvido um outro detetor de balanceamento de indução direcionado para pesquisas arqueológicas, usando 3 bobinas coplanares, sendo duas transmissoras e uma receptora, numa mesma unidade. Devido a disposição das bobinas, o sistema permite detectar anomalias condutoras rasas, no eixo da bobina transmissora maior. Os circuitos de geração de campo magnético e de detecção são análogos aos já descritos.

\section{Construção dos circuitos eletrônicos e das bobinas do transmissor Tx e do receptor $\mathbf{R x}$.}

Baseando-se nas informações de circuitos comerciais e nos dados de publicações existentes, foram adotados vários parâmetros para desenvolvimento do projeto. $\mathrm{Na}$ geometria das bobinas transmissorareceptora utilizou-se o conceito de número de indução baixo, para conversão da componente em quadratura de Hs diretamente em valores de condutividade elétrica aparente $(\mathrm{mS} / \mathrm{m})$. Estes cálculos são feitos em tempo real por um circuito microcontrolador RISC da série PIC 16F877A de baixo custo, e apresentados num display de 2 linhas de 16 caracteres cada (Fig2).

O espaçamento interbobinas adotado foi de 3,70 metros e o diâmetro externo dos 2 tubos suporte de PVC das bobinas foi de $5 \mathrm{~cm}$. Estes 2 tubos de comprimento $175 \mathrm{~cm}$ deslizam dentro de um tubo de PVC de diâmetro interno $5 \mathrm{~cm}$ e comprimento de $150 \mathrm{~cm}$. O suporte foi dividido em 3 partes, para facilidade de transporte. $O$ console do equipamento está preso no meio do tubo de PVC de diâmetro $6 \mathrm{~cm}$ externo (Fig1).

O formato das 2 bobinas é eliptico de modo que os eixos das mesmas fiquem posicionados de $54,74^{\circ}$, e 0 acoplamento magnético entre as bobinas Tx e Rx seja nulo As 2 bobinas foram confeccionadas, de modo que coubessem dentro de 2 tubos de PVC, comprimento total $20 \mathrm{~cm}$ e diâmetro: interno $50 \mathrm{~mm}$ (Fig.1). Os carretéis elípticos das bobinas têm eixo maior de $12 \mathrm{~cm}$ e menor de $4,5 \mathrm{~cm}$, fixados na inclinação citada acima. O tubo que suporta a bobina receptora $\mathrm{Rx}$ pode ser rotacionado para um ajuste fino do acoplamento nulo entre $\mathrm{Rx}$ e $\mathrm{Tx}$.

A bobina transmissora Tx tem 300 espiras e indutância de $30 \mathrm{mH}$. A corrente média é de $250 \mathrm{~mA}$, que permite tempo de uso contínuo de 20 horas usando baterias gell-cell de 12VDC/8Ah. A frequencia de operação é de $39,2 \mathrm{kHz}$, gerado por um multivibrador astável de precisão (555), que polariza 2 multivibradores tipo D (CD4013) em cascata, em cujas saídas têm- se sinais perfeitamente quadrados de 19,6 , e de $9,8 \mathrm{kHz}$. O sinal de $9,8 \mathrm{kHz}$ é aplicado no módulo de potência e também serve de referência para demodulação do sinal em fase do campo secundário $\mathrm{Hs}$ em $\mathrm{Rx}$. As 2 saídas dos multivibradores D polarizam o defasador de $90^{\circ}$ (CD4538) para detecção do sinal em quadratura do campo devido a anomalia. O circuito de chaveamento polariza um transistor hexfet de potência IRF540, que alimenta o primário de 50 espiras de um transformador de núcleo toroidal de ferrite. O enrolamento secundário é constituído de 200 espiras que alimenta diretamente a bobina transmissora no modo LC ressonante paralelo (Fig.2). Neste ajuste ressonante o campo magnético variável $\mathrm{Hp}$ está rigorosamente em fase com o sinal da porta do fet IRF540. Ao redor desta bobina transmissora existe um enrolamento de 10 espiras, usada para compensação fina do campo primário na bobina receptora. $\mathrm{O}$ sinal deste solenóide também é usado para medida do campo primário Hp (Fig 2).

A bobina receptora $\mathrm{Rx}$ tem 3000 espiras de fio esmaltado fino, e a indutância é da ordem de $150 \mathrm{mH}$. Sua saída está conectada a um amplificador no modo diferencial (Fig.2) que proporciona um ganho de 20x. 0 próximo estágio é um filtro rejeição de $60 \mathrm{~Hz}$, seguido de um amplificador inversor de ganho ajustável (máximo de $100 \mathrm{x}$ ). O sinal do inversor é aplicado em 2 circuitos demoduladores sincronos D1 e D2 com filtros passa baixas nas saídas, para obtenção dos sinais DC em fase e em quadratura do campo magnético variável Hs . Cada demodulador sincrono é constituido de um circuito muxdemux CD4053 responsável pelo chaveamento controlado pelo sinal quadrado de referência proveniente do circuito REF do transmissor. Para ter-se o sinal em quadratura do campo $\mathrm{Hs}$, o sinal de referência é tratado por 1 circuito digital de atraso de fase ajustável (Douglas, 1996),em REF, formado de um monoestável CD4538 . O sinal em quadratura do campo secundário Hs é usado para medida da condutividade elétrica aparente e o sinal em fase, dá informações úteis de presença de materiais ferro- ferrimagnéticos em subsuperfície.

Para pesquisas rasas, por ex. Arqueologia, foi desenvolvido um sistema constituído de duas bobinas transmissoras e uma receptora, no modo coplanar, dentro de um mesmo conjunto. Neste protótipo, a bobina transmissora externa tem diâmetro de $25 \mathrm{~cm}, 300$ espiras, e uma indutância de $20 \mathrm{mH}$. A segunda bobina transmissora tem diâmetro de $10 \mathrm{~cm}$ e 100 espiras, e tangencia a bobina maior na parte interna. Este enrolamento está em oposição de fase em relação à maior, e a corrente circulante é a mesma nas duas bobinas transmissoras. A bobina receptora ou exploradora de 800 espiras e indutância $65 \mathrm{mH}$ é posicionada no interior e no mesmo plano da bobina transmissora maior, de modo que a tensão em sua saída seja nula, i. é, o fluxo magnético total é nulo, em todo instante 
Todos os circuitos eletrônicos do transmissor e do receptor são análogos aos descritos anteriormente.

A sensibilidade de detecção para um alvo condutor de $10 \times 10 \mathrm{~cm}$ é da ordem de $1 \mathrm{~m}$.

Como o detetor opera em frequencia baixa $(6 \mathrm{kHz})$ obtida a partir de um multivibrador astável de precisão, o equipamento tem boa resolução e penetração em terreno argiloso.

$\mathrm{Na}$ versão futura, a bobina transmissora terá um diâmetro superior a $100 \mathrm{~cm}$, feita de carretel de fibra de vidro, para ter- se uma maior penetração (da ordem de 3 $\mathrm{m})$, para alvos condutores de dimensões da ordem de $30 \times 30 \mathrm{~cm}$.

\section{Referências}

Bastianon,D., 1996. Desenvolvimento de um sistema de medida de resistividade elétrica complexa para aplicações. Dissertação de Mestrado, IAGUSP,pp 77

Doebelin, E. O.,1986. Measurement SystemsApplication and Design. McGraw- Hill Book Company, pp 875.

Sinha, A.K \& Collett, L.S,1973. Electromagnetic fields of oscillating magnetic dipoles placed over a multilayer conducting earth: Geol.Surv Can. Paper 73-25.

Tocci, R.J., 1995. Digital Systems-Principles \& Applications. Prentice Hall, pp827.

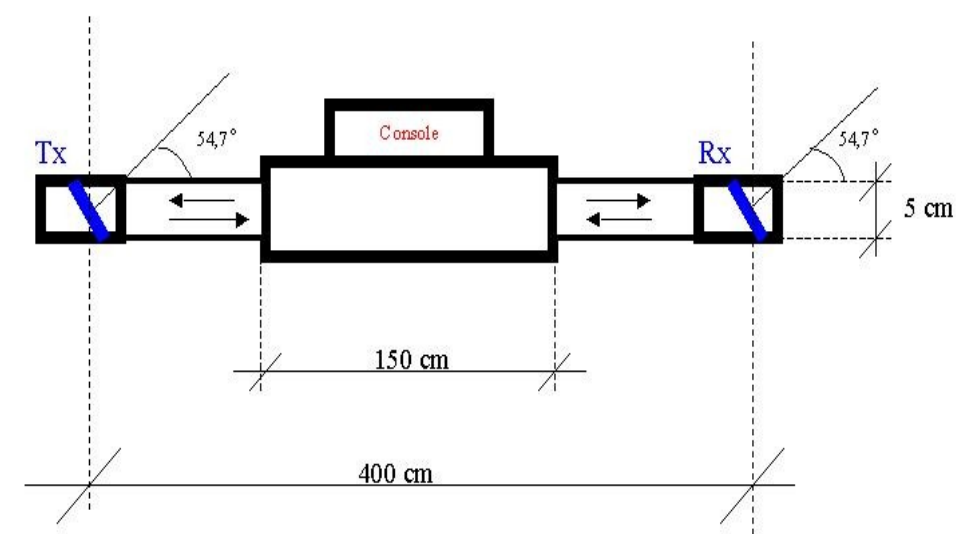

Fig1- Diagrama do equipamento eletromagnético, mostrando o posicionamento das bobinas transmissora Tx e receptora $\mathrm{Rx}$, paralelas

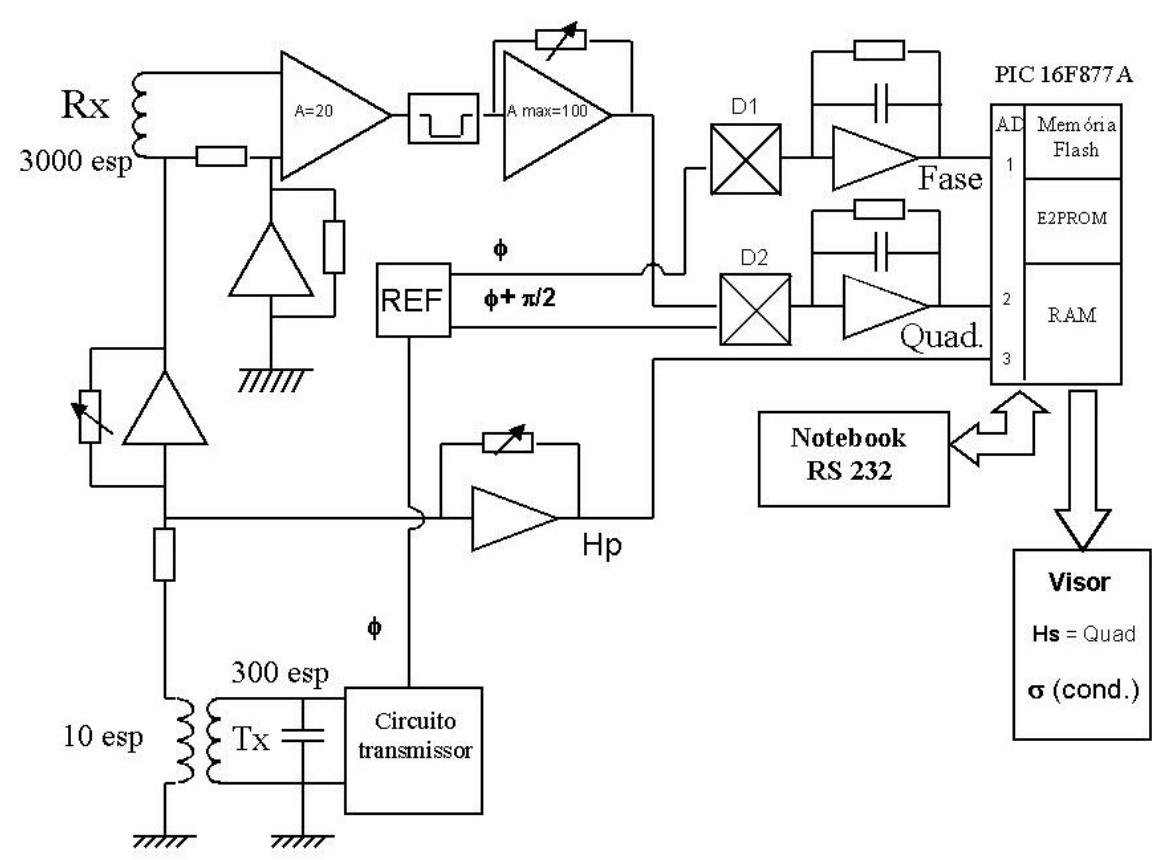

Fig.2- Diagrama elétrico dos circuitos associados ao transmissor e receptor do equipamento eletromagnético. 